\title{
Development and Regeneration of Sensory Transduction in Auditory Hair Cells Requires Functional Interaction Between Cadherin-23 and Protocadherin-15
}

\author{
Andrea Lelli, ${ }^{1 \star}$ Piotr Kazmierczak, ${ }^{3 \star}$ Yoshiyuki Kawashima, ${ }^{4}$ Ulrich Müller, ${ }^{3}$ and Jeffrey R. Holt ${ }^{1,2}$ \\ Departments of ${ }^{1}$ Neuroscience and ${ }^{2}$ Otolaryngology, University of Virginia School of Medicine, Charlottesville, Virginia 22908, ${ }^{3}$ Department of Cell Biology, \\ Dorris Neuroscience Center, The Scripps Research Institute, La Jolla, California 92037, and ${ }^{4}$ Section on Gene Structure and Function, National Institute on \\ Deafness and Other Communication Disorders, National Institutes of Health, Rockville, Maryland 20850
}

\begin{abstract}
Tip links are extracellular filaments that connect pairs of hair cell stereocilia and convey tension to mechanosensitive channels. Recent evidence suggests that tip links are formed by calcium-dependent interactions between the N-terminal domains of cadherin-23 (CDH23) and protocadherin-15 (PCDH15). Mutations in either CDH23 or PCDH15 cause deafness in mice and humans, indicating the molecules are required for normal inner ear function. However, there is little physiological evidence to support a direct role for $\mathrm{CDH} 23$ and PCDH15 in hair cell mechanotransduction. To investigate the contributions of $\mathrm{CDH} 23$ and PCDH15 to mechanotransduction and tip-link formation, we examined outer hair cells of mouse cochleas during development and after chemical disruption of tip links. We found that tip links and mechanotransduction with all the qualitative properties of mature transduction recovered within $24 \mathrm{~h}$ after disruption. To probe tip-link formation, we measured transduction currents after extracellular application of recombinant CDH23 and PCDH15 fragments, which included putative interaction domains (EC1). Both fragments inhibited development and regeneration of transduction but did not disrupt transduction in mature cells. PCDH15 fragments that carried a mutation in EC1 that causes deafness in humans did not inhibit transduction development or regeneration. Immunolocalization revealed wild-type fragments bound near the tips of hair cell stereocilia. Scanning electron micrographs revealed that hair bundles exposed to fragments had a reduced number of linkages aligned along the morphological axis of sensitivity of the bundle. Together, the data provide direct evidence implicating CDH23 and PCDH15 proteins in the formation of tip links during development and regeneration of mechanotransduction.
\end{abstract}

\section{Introduction}

A central element in the prevailing model of hair cell mechanotransduction is an extracellular filament known as the tip link. Tip links were discovered $>25$ years ago in scanning electron micrographs (Pickles et al., 1984) where they were observed extending from the tips of stereocilia to the sides of their adjacent taller neighbors. Tip links are thought to convey tension to mechanosensitive transduction channels by connecting pairs of stereocilia along a morphological axis that defines the physiological polarity of the hair bundle. Their functional significance is clear, as rupture of tip links with low extracellular calcium renders hair bundles insensitive to mechanical stimulation (Assad et al., 1991; Marquis and Hudspeth, 1997). After return of extracellular calcium, tip links and mechanotransduction regenerate (Zhao et al., 1996; Jia et al., 2009).

\footnotetext{
Received April 15, 2010; revised May 26, 2010; accepted June 8, 2010.

This work was supported by National Institutes of Health (NIH)/National Institute on Deafness and Other Communication Disorders Grants DC05439 (J.R.H.), DC05965, and DC07704 (U.M.), and NIH intramural research fund Z01-DC-000060 (Y.K.). We thank members of the Holt/Géléoc and Corwin laboratories for helpful discussions and Journal of Neuroscience reviewers for their constructive comments.

${ }^{*}$ A.L. and P.K. contributed equally to the work.

Correspondence should be addressed to Dr. Jeffrey R. Holt, Departments of Neuroscience and Otolaryngology, University of Virginia, MR4, Room 5126, Box 801392, Charlottesville, VA 22908-1392. E-mail: jeffholt@virginia.edu. DOI:10.1523/JNEUROSCI.1949-10.2010

Copyright $\odot 2010$ the authors $\quad 0270-6474 / 10 / 3011259-11 \$ 15.00 / 0$
}

Immunolocalization evidence suggests that tip links are composed of two members of the cadherin superfamily: cadherin-23 (CDH23) (Siemens et al., 2004; Söllner et al., 2004) and protocadherin-15 (PCDH15) (Ahmed et al., 2006). Kazmierczak et al. (2007) proposed that tip links are formed by a heterophilic interaction between homodimers with $\mathrm{PCDH} 15$ at the lower end and $\mathrm{CDH} 23$ at the upper end. The crystal structure of the $\mathrm{N}$ terminus of $\mathrm{CDH} 23$ supports a novel calcium-dependent interaction with the N-terminal domain of PCDH15 (Sotomayor et al., 2010). In this arrangement, the two molecules form a linear array of $38,4 \mathrm{~nm}$ cadherin domains, $\sim 150 \mathrm{~nm}$ in length, sufficient to span the gap between the tip of one sterocilium and the side of its adjacent taller neighbor (Furness et al., 2008).

Despite the growing body of immunolocalization data, there is little physiological evidence that supports a direct role for $\mathrm{CDH} 23$ and PCDH15 in hair cell transduction. Mutations in either PCDH15 or CDH23 cause deafness in humans and mice, indicating an essential role for these molecules in auditory function (Ahmed et al., 2001; Alagramam et al., 2001; Di Palma et al., 2001), but it is not clear whether the deficit is the result of a disruption in hair bundle morphogenesis or a direct effect on the transduction apparatus. Indeed, CDH23 (Siemens et al., 2004; Lagziel et al., 2005; Michel et al., 2005) and PCDH15 (Pawlowski et al., 2006; Senften et al., 2006) may be important for development of normal hair bundle morphology because they contribute 
to formation of kinociliary links and transient lateral links that connect hair cell stereocilia into a bundle during development. Although transient lateral links are not present in functionally mature hair cells, PCDH15 and CDH23 continue to be expressed near stereocilia tips (Siemens et al., 2004; Rzadzinska et al., 2005; Ahmed et al., 2006; Kazmierczak et al., 2007). However, one recent report suggests that $\mathrm{CDH} 23$ is not required for the formation of tip links (Rzadzinska and Steel, 2009).

To examine the contributions of $\mathrm{CDH} 23$ and PCDH15 to tip links and hair cell transduction, we deflected hair bundles and recorded mechanotransduction currents after extracellular application of CDH23 and PCDH15 fragments (Kazmierczak et al., 2007) before, during, and after tip-link development and regeneration. We reasoned that the fragments might bind to the endogenous molecules and outcompete their endogenous partners and thereby block the formation of tip links. Here, we characterize development and regeneration of hair cell mechanotransduction and provide direct physiological evidence that supports the notion that tip links are formed by a heterophilic, N-terminal interaction between CDH23 and PCDH15.

\section{Materials and Methods}

Expression and purification of $\mathrm{CDH} 23$ and $\mathrm{PCDH} 15$ fragments. For the electrophysiology studies, we used the full-length ectodomain of $\mathrm{CDH} 23$ with the $\mathrm{C}$ terminus fused to a His tag (CDH23-His) or the first 11 cadherin repeats of $\mathrm{CDH} 23$ fused to the Fc domain of the Ig heavy chain (CDH23F11-Fc) (supplemental Fig. 1, available at www.jneurosci.org as supplemental material). The full-length ectodomain of PCDH15 was fused to a Myc His tag (PCDH15-His) at the $\mathrm{C}$ terminus or an Fc domain (PCDH15-Fc). The expression vectors and methods for the generation of recombinant $\mathrm{CDH} 23$ and $\mathrm{PCDH} 15$ fragments were described previously (Kazmierczak et al., 2007). Briefly, HEK293 cells were grown in DMEM (Invitrogen) containing 10\% fetal bovine serum (FBS) (Gemini Products), $1 \times$ penicillin/streptomycin and glutamine (Invitrogen). Cells were transfected using FuGENE6 reagent (Roche). Twelve hours after transfection, the media was replaced with serum-free DMEM/F12 supplemented with antibiotics and glutamine. Forty-eight hours later, the media were collected and subjected to chromatography over Ni-NTA agarose (Qiagen). His-tagged proteins were eluted with $100 \mathrm{~mm}$ imidazole in $50 \mathrm{~mm}$ Tris- $\mathrm{HCl}$ and $150 \mathrm{~mm} \mathrm{NaCl}, \mathrm{pH}$ 7.5. Purified proteins were separated on $7.5 \%$ SDS-PAGE gels and analyzed by silver staining using a kit (Bio-Rad). The concentrations of $\mathrm{CDH} 23$-His and PCDH15-His were $233 \mathrm{ng} / \mu \mathrm{l}$ and $100 \mathrm{ng} / \mu \mathrm{l}$, respectively. CDH23 and PCDH15 tagged with human IgG1 Fc were produced in a similar way. For control experiments with integrin fragments, the soluble extracellular domain Histagged integrin $\alpha 8 \beta 1$ heterodimer (INTG-His) was expressed and purified as previously described (Müller et al., 1997). Purified proteins were separated on $7.5 \%$ SDS-PAGE gels and analyzed by silver staining using a kit (Bio-Rad). Finally, His-tagged fragments were dialyzed for $24 \mathrm{~h}$ in a Slide-A-Lyser cassette (molecular weight cutoff, $7000 \mathrm{Da}$; Pierce) in a solution containing the following (in $\mathrm{mm}$ ): $144 \mathrm{NaCl}, 0.7$ $\mathrm{NaH}_{2} \mathrm{PO}_{4}, 5.8 \mathrm{KCl}, 1.3 \mathrm{CaCl}_{2}, 0.9 \mathrm{MgCl}_{2}$, and $10 \mathrm{HEPES}-\mathrm{NaOH}$, adjusted to $\mathrm{pH}$ 7.4. Media containing the Fc-tagged fragment were concentrated with Microcon filter devices (molecular weight cutoff, $100 \mathrm{kDa}$; Millipore) and resuspended in dialyzing solution.

Tissue preparation. Organs of Corti were harvested from Swiss Webster mice (Hilltop Lab Animals and Taconic Farms) at postnatal day 0 (P0) following protocols approved by the Animal Care Committee of the University of Virginia (Protocol \#3123). For experiments that examined transduction regeneration, the basal turn was excised and placed on a round coverslip previously coated with Cell-Tak (BD Bioscience). For experiments that examined transduction development, we harvested the apical turn and placed it in culture for up to $4 \mathrm{~d}$. To reduce the final volume of medium during fragment application, a small plastic cylinder was attached to the coverslip with vacuum grease. Cultures were bathed in MEM (Invitrogen) supplemented with 5\% FBS and kept in an incu- bator at $37^{\circ} \mathrm{C}$ and $5 \% \mathrm{CO}_{2}$. As indicated in the Results section, cochlear cultures were treated for $15 \mathrm{~min}$ with a low-calcium EGTA solution that contained the following (in mM): $140 \mathrm{NaCl}, 0.7 \mathrm{NaH}_{2} \mathrm{PO}_{4}, 5.8 \mathrm{KCl}, 2.2$ $\mathrm{MgCl}_{2}$, 5 EGTA, $5.6 \mathrm{D}$-glucose, and 10 HEPES-NaOH, adjusted to $\mathrm{pH}$ 7.4 and $320 \mathrm{mOsmol} / \mathrm{kg}$, and supplemented with vitamins (1:50) and amino acids (1:100), at the same concentrations present in MEM. The cultures were bathed in $200 \mu \mathrm{l}$ of MEM together with different volumes of the fragment solution. Twelve hours after fragment application, the cylinders were removed and experiments were performed. For the washout experiments, cochleas that had been exposed to fragments were retreated with the low-calcium EGTA solution for $15 \mathrm{~min}$, followed by a vigorous wash and then bathed in MEM supplemented with 5\% FBS and returned to the incubator for an additional $24 \mathrm{~h}$.

Immunostaining. For these experiments, we used $\mathrm{CDH} 23$ fragments that included the first 11 cadherin repeats (supplemental Fig. 1, available at www.jneurosci.org as supplemental material). The PCDH15 fragments included the entire ectodomain. The fragments were fused to the human IgG1 Fc domain as previously described (Kazmierczak et al., 2007). Sensory epithelia were fixed in 4\% paraformaldehyde in PBS $12 \mathrm{~h}$ after fragment application and permeabilized with $0.1 \%$ Triton X-100. After block with $3 \%$ normal goat serum in PBS for 1-2 h, samples were stained with FITC-conjugated goat anti-human IgG Fc antibody (Invitrogen) and counterstained with Alexa Fluor 546 phalloidin (Invitrogen). Epithelia were mounted on coverslips bathed in Slowfade Gold reagent (Invitrogen) and viewed with a Zeiss 510 confocal laser-scanning microscope. Images were analyzed using Zeiss Confocal Assistant software and Adobe Photoshop CS.

Scanning electron microscopy. Samples were prepared using the OTOTO method (Furness and Hackney, 1985), which alternates osmium tetroxide $\left(\mathrm{OsO}_{4}\right)$ and thiocarbo-hydrazide $(\mathrm{TCH})$ treatment and does not require sputtercoating. At P0 plus $2 \mathrm{~d}$ in vitro, cultures were fixed for $1 \mathrm{~h}$ at $4^{\circ} \mathrm{C}$ with $2.5 \%$ glutaraldehyde in $0.1 \mathrm{M}$ sodium cacodylate buffer that contained $2 \mathrm{mM} \mathrm{CaCl}_{2}, \mathrm{pH}$ 7.2. Cultures were then stained with $1 \% \mathrm{OsO}_{4}$ in cacodylate buffer for $1 \mathrm{~h}$. After six washes, samples were bathed for $20 \mathrm{~min}$ in a saturated aqueous solution of $\mathrm{TCH}$, rinsed six times with distilled water, immersed in $1 \% \mathrm{OsO}_{4}$ for $1 \mathrm{~h}$, and washed six more times. The sequence was repeated twice. The tissue was then dehydrated in an ethanol series and dried with a CPD 030 Critical Point Dryer (Bal-tec). Samples were mounted and viewed with a Hitachi S-4800 fieldemission scanning electron microscope, at $1 \mathrm{kV}$ acceleration voltage.

Electrophysiological recording. Hair cells were viewed from above the apical surface using an upright Axioskop FS microscope (Zeiss) equipped with a $63 \times$ water-immersion lens and differential interference contrast optics. Recording pipettes (2-5 M 2 ) were pulled from R-6 soda glass (King Precision Glass) and filled with intracellular solution that contained the following (in mM): $135 \mathrm{KCl}, 5$ EGTA-KOH, 10 HEPES, 2.5 $\mathrm{K}_{2} \mathrm{ATP}, 3.5 \mathrm{MgCl}_{2}$, and $0.1 \mathrm{CaCl}_{2}, \mathrm{pH}$ 7.4. Currents were measured in standard artificial perilymph that contained the following (in $\mathrm{mM}$ ): 144 $\mathrm{NaCl}, 0.7 \mathrm{NaH}_{2} \mathrm{PO}_{4}, 5.8 \mathrm{KCl}, 1.3 \mathrm{CaCl}_{2}, 0.9 \mathrm{MgCl}_{2}, 5.6 \mathrm{D}$-glucose, and 10 HEPES- $\mathrm{NaOH}$, adjusted to $\mathrm{pH} 7.4$ and $320 \mathrm{mOsmol} / \mathrm{kg}$. Vitamins (1:50) and amino acids (1:100) were added from concentrates (Invitrogen). Currents were recorded in whole-cell, voltage-clamp mode at $\sim 22^{\circ} \mathrm{C}$ with an Axopatch Multiclamp 700A (Molecular Devices) at a holding potential of $-64 \mathrm{mV}$. Data were filtered at $10 \mathrm{kHz}$ with a low-pass Bessel filter, digitized at $\geq 20 \mathrm{kHz}$ with a 12 bit acquisition board (Digidata 1322) and pClamp 8.2 (Molecular Devices), and stored on disk for offline analysis using OriginPro 7.1 (OriginLab). Results are presented as means \pm SE.

Mechanical stimuli were delivered as previously described (Stauffer and Holt, 2007). Briefly, stiff glass probes were mounted on a PICMA piezoactuator (Physik Instruments), which was driven by an ENV400 Amplifier (Piezosystem Jena). Probe tips were fired polished (H602, WPI) with 3-5 $\mu$ m diameter to fit the "V-shaped" hair bundle (Stauffer and Holt, 2007). Deflections were evoked with voltage steps that were low pass filtered with an eight-pole Bessel filter (Khron-Hite) at $20 \mathrm{kHz}$ to eliminate residual pipette resonance. 
A Control
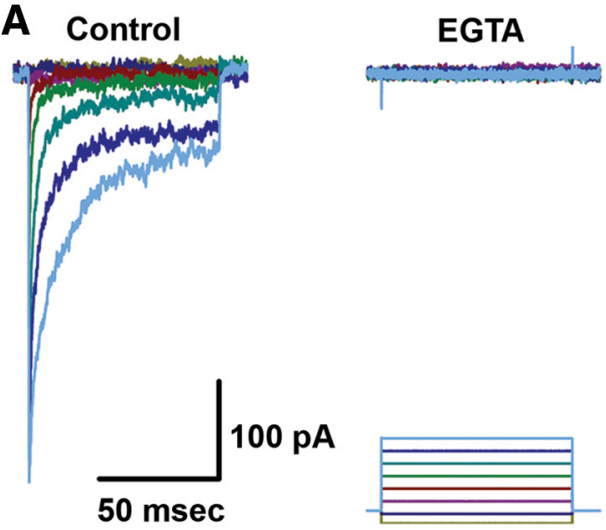

B
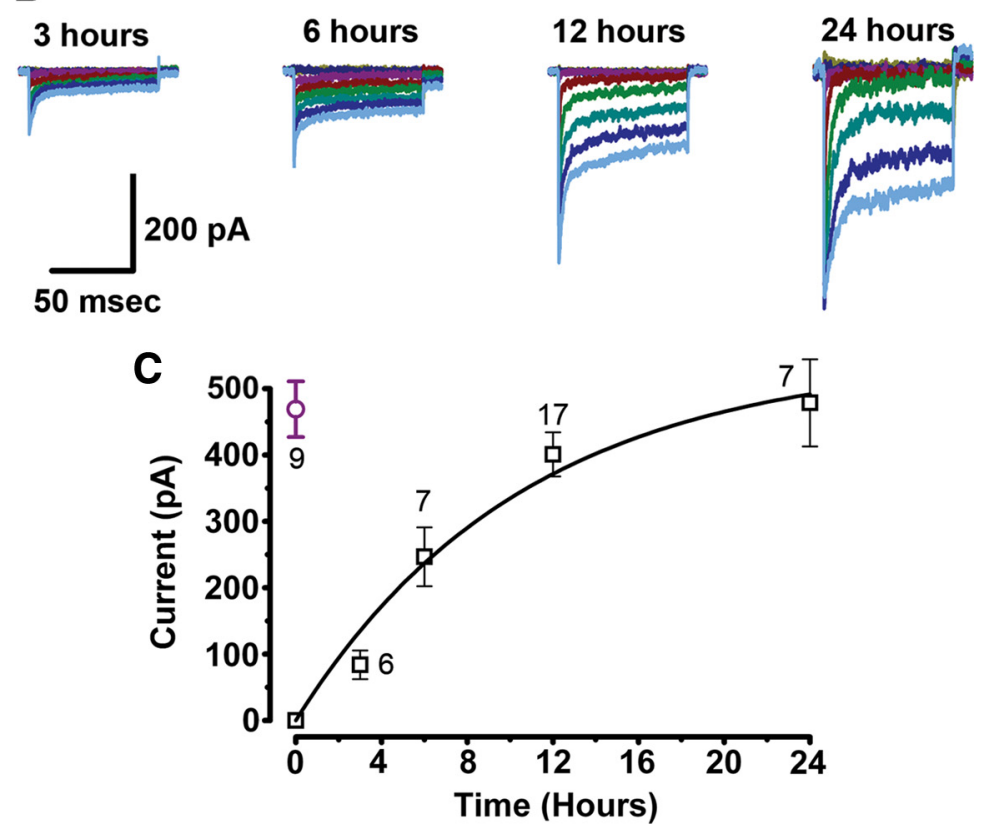

Figure 1. Recovery of transduction current after EGTA treatment. $\boldsymbol{A}$, Representative families of transduction currents recorded from outer hair cells in control conditions (left), immediately after EGTA treatment (center), and $12 \mathrm{~h}$ after EGTA treatment and return to standard calcium (right). The cells were voltage clamped at $-64 \mathrm{mV}$. Hair bundles were deflected, as indicated by the stimulation protocol shown below, with deflections that ranged between -0.2 and $1.2 \mu \mathrm{m}$ in $0.2 \mu \mathrm{m}$ increments. The scale bar applies to all three current families. $\boldsymbol{B}$, Time course of current recovery. Representative families of transduction currents recorded $3,6,12$, and $24 \mathrm{~h}$ after EGTA treatment. Deflections ranged between -0.2 and $1.2 \mu \mathrm{m}$ in $0.2 \mu \mathrm{m}$ increments. The scale bar applies to all four current families. C, Mean maximal transduction current amplitudes (squares) plotted as a function of recovery time. The number of cells at each time point is shown next to the data point. The data were fitted with a single exponential equation of the form: $I=I_{\text {Max }}\left(1-e^{-t / \tau}\right)$ with $I_{\text {Max }}=-549 \mathrm{pA}, \tau=10$.6h. For comparison, a single data point (circle) from age (P2) and region (base) matched control outer hair cells is reprinted from Lelli et al. (2009).

\section{Results}

Recovery of transduction after EGTA treatment

We began by examining the recovery of transduction after disruption of tip links using low-calcium solutions that contained 5 mM EGTA. Previously, it has been shown that calcium chelation breaks tip links in frog (Assad et al., 1991; Marquis and Hudspeth, 1997) and chicken (Zhao et al., 1996) hair cells. Gale et al. (2001) showed that FM1-43 uptake is reduced in mouse cochlear hair cells exposed to EGTA. To extend these observations, we harvested the cochlear basal turn from neonatal mice at P0. After $1 \mathrm{~d}$ in culture, explants were treated for 15 min with a low-calcium solution supplemented with $5 \mathrm{~mm}$ EGTA. Mechanoelectrical transduction currents were recorded from outer hair cells using the whole-cell, tight-seal technique. Hair bundles were deflected with a stiff glass probe mounted on a fast piezo actuator (Stauffer and Holt, 2007). We were unable to detect transduction currents immediately after EGTA treatment $(n=5)$ (Fig. 1A, EGTA), whereas untreated control hair cells had robust transduction currents (Fig. $1 \mathrm{~A}$, Control). These data are consistent with the notion that tip links are severed by solutions in which the calcium concentration is $<1$ $\mu \mathrm{M}$ (Assad et al., 1991; Zhao et al., 1996; Marquis and Hudspeth, 1997; Furness et al., 2008).

In the chicken basilar papilla, recovery of transduction currents after EGTA treatment has been reported after calcium was restored to the culture medium (Zhao et al., 1996). Gale et al. (2001) demonstrated recovery of FM1-43 uptake after 12-24 h in mouse cochlear hair cells, and Jia et al. (2009) reported recovery of transduction currents in gerbil hair cell cultures after $24 \mathrm{~h}$. In each case, the authors suggested that reformation of tip links and the transduction apparatus had occurred. In our experiments, when the EGTA-treated cultures were incubated in standard culture media (MEM with 1.3 $\mathrm{mM} \mathrm{Ca}^{2+}$ ) for $12 \mathrm{~h}$, we found that transduction currents returned and that the current had maximal amplitudes similar to controls (Fig. 1A, Recovery). We measured recovered transduction currents from 17 outer hair cells: the mean maximal transduction current was $-401 \pm 33$ pA. To characterize the time course of transduction current recovery, we performed similar experiments at $3,6,12$, and $24 \mathrm{~h}$ after EGTA treatment. Representative currents are shown for each time point (Fig. $1 B$ ). We also plotted the mean maximal current amplitudes as a function of recovery time and fit the data with an exponential curve (Fig. 1C). After $12 \mathrm{~h}$, the amplitude of the transduction currents was $86 \%$ of that reported for P2 basal turn outer hair cells (Fig. 1C, circle) (Lelli et al., 2009), and the recovery was complete $24 \mathrm{~h}$ after EGTA treatment. The exponential fit revealed a time constant of $10.6 \mathrm{~h}$. Interestingly, the time course of transduction current recovery closely paralleled the time course of recovery from noise induced temporary shifts in hearing threshold (Zhao et al., 1996; Husbands et al., 1999), suggesting that regeneration of tip links and the transduction apparatus might be an important cellular mechanism that underlies the recovery of auditory function after noise exposure.

We wondered whether the recovery in current amplitude was paralleled by a recovery of other biophysical aspects of hair cell transduction. In contrast to chick hair cells (Zhao et al., 1996) but consistent with gerbil hair cells (Jia et al., 2009), mouse cochlear hair cells had prominent adaptation (the decline of transduction current in the presence of a constant stimulus) at the earliest time point we examined, $3 \mathrm{~h}$ after EGTA treatment. We examined the 
time course of hair cell adaptation and the shape of the stimulus-response relationship at several points during the recovery. Current traces were selected that had peak currents approximately equal to the halfmaximal response, the point at which the activation curve is most linear and the time course of the current decline approximately parallels the underlying shift of the activation curve (Shepherd and Corey, 1994; Stauffer and Holt, 2007). The selected traces were fit with a double exponential equation (Vollrath and Eatock, 2003). We found both fast and slow components of adaptation were present $3 \mathrm{~h}$ after EGTA (Fig. 2A), which suggested that the mechanisms of fast and slow adaptation are tightly linked with the transduction recovery process. However, the time constants were slower than in control cells and became faster as the recovery proceeded (Fig. 2A). The trend toward faster adaptation is illustrated by the mean time constants measured from 37 outer hair cells shown as a function of recovery time (Fig. $2 B$ ).

We also noted that as the recovery proceeded, the sensitivity of the cells became sharper. The greater sensitivity is illustrated in the representative stimulusresponse curves, which became progressively steeper at 3, 12, and $24 \mathrm{~h}$ after EGTA exposure (Fig. 2D). To quantify the change in sensitivity, we plotted the $10-90 \%$ operating range for 37 cells as a function of recovery time (Fig. $2 E$ ).

In a previous study, we characterized the development of hair cell adaptation and sensitivity and found a similar trend toward faster adaptation and greater sensitivity as a function of development (Lelli et al., 2009). We suggest that the parallel changes in these properties of hair cell transduction indicate that similar molecular mechanisms may contribute to both development and regeneration of hair cell transduction.

Next we asked whether regeneration of hair cell transduction in mice requires new protein synthesis. We added $1 \mu \mathrm{g} / \mathrm{ml}$ of the protein synthesis inhibitor cycloheximide (CXM) to the medium and recorded transduction currents $24 \mathrm{~h}$ later. We found no significant difference between cultures exposed to both EGTA and CXM $(-239 \pm 47 \mathrm{pA}, n=12)$ and CXM-treated controls $(-212 \pm 48 \mathrm{pA}, n=10)$. The similar amplitude between EGTAtreated and untreated cells suggests that regeneration of transduction does not require new protein synthesis, but rather takes advantage of a readily available pool of transduction molecules. This result is consistent with a previous report that showed a similar concentration of CXM was sufficient to block protein synthesis in hair cells but did not block regeneration of tip links (Zhao et al., 1996).

The mean amplitude of the transduction currents recorded from CXM-exposed cultures, regardless of whether or not the cells had been exposed to EGTA, was approximately half of that recorded from untreated outer hair cells of the equivalent devel- opmental stage (P2) and region but approximately the same as control currents at P1 (Lelli et al., 2009). Because CXM is a broadspectrum protein synthesis inhibitor, we suspect the relative transduction current reduction was due to the $24 \mathrm{~h}$ halt in global protein synthesis and development rather than a specific effect on tip-link molecules.

\section{Exogenous CDH23 and PCDH15 fragments inhibit transduction recovery}

A recent study (Kazmierczak et al., 2007) presented immunolocalization evidence that placed PCDH15 at the tips of shorter stereocilia and $\mathrm{CDH} 23$ along the side of the adjacent taller stereocilia. Kazmierczak et al. (2007) also showed that the two molecules interact at their N-terminal tips to form filaments of sufficient length to span the distance between adjacent stereocilia. Last, they found that the interaction was calcium dependent. Although these data are consistent with the hypothesis that tip links are formed by PCDH15 and CDH23, the Kazmierczak et al. (2007) study did not address whether the proteins are required for mechanotransduction. To test the hypothesis that a functional interaction between the PCDH15 and $\mathrm{CDH} 23$ is required 
A

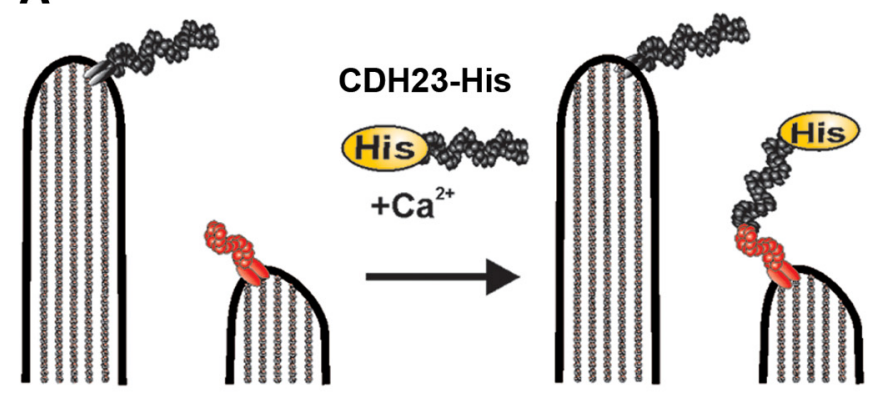

B

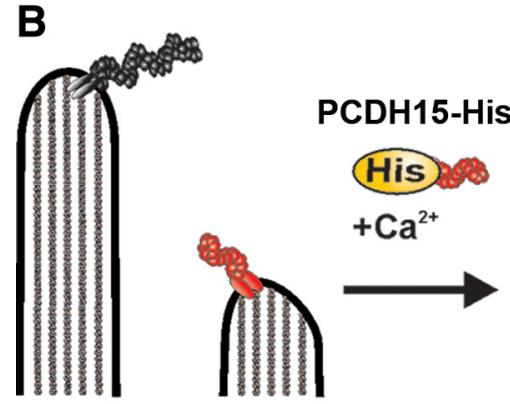

C
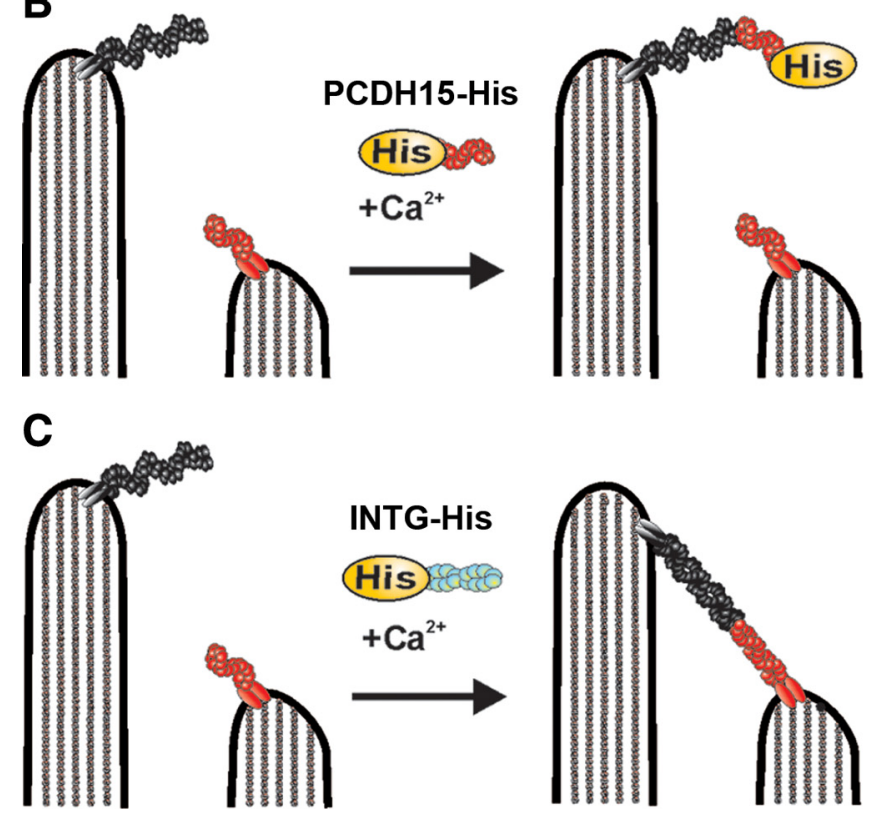
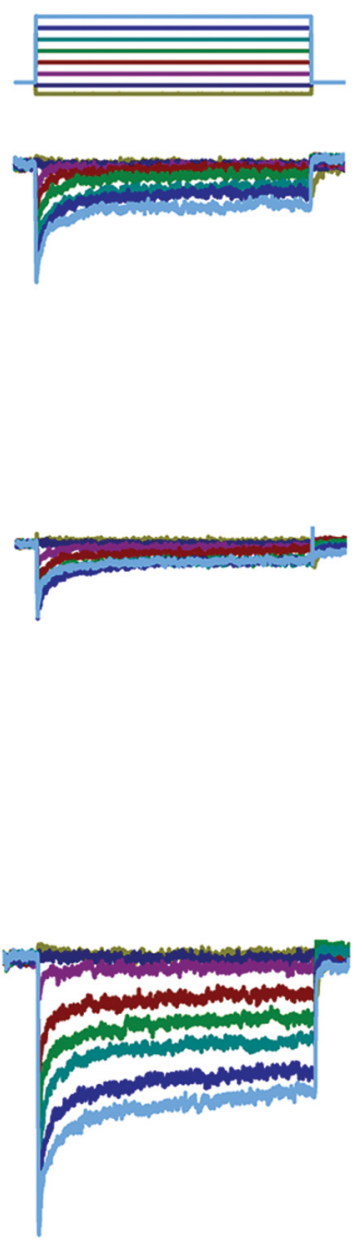

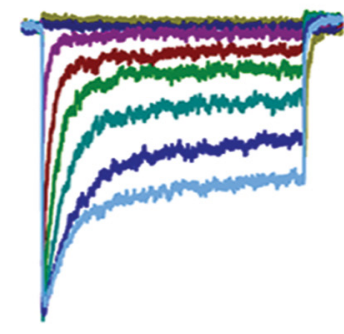

WASHOUT
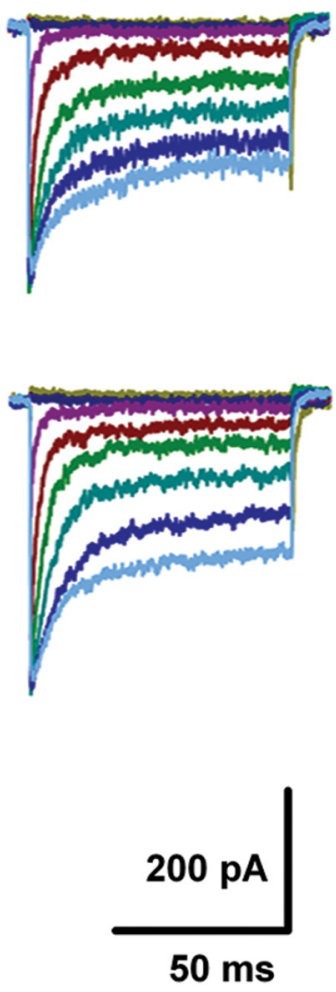

Figure 3. $\quad \mathrm{CDH} 23$ and $\mathrm{PCDH} 15$ fragments interfere with transduction current recovery. Schematic drawing of pairs of stereocilia illustrating the experimental paradigm. $\mathrm{CDH} 23$ fragments (CDH23-His), PCDH15 fragments (PCDH15-His), or integrin fragments (INTG-His) were added to the culture media immediately after EGTA treatment (left). We hypothesize that CDH23-His and $\mathrm{PCDH} 15$-His bind the $\mathrm{N}$ terminus of its endogenous binding partner to prevent reformation of full-length tip links. $A, A$ representative family of transduction currents recorded $12 \mathrm{~h}$ after $\mathrm{EGTA}$ treatment and application of $\mathrm{CDH} 23$-His (middle). Twenty-four hours after a second treatment with EGTA and a vigorous washout of CDH23-His, the currents recovered (right). The stimulus protocol is shown at the top. Deflections ranged between -0.2 and $1.2 \mu \mathrm{m}$ in $0.2 \mu \mathrm{m}$ increments. The protocol and scale bars apply to all current families. $\boldsymbol{B}$, A representative family of transduction currents recorded $12 \mathrm{~h}$ after application of PCDH15-His (middle). Twenty-four hours after a second treatment with EGTA and a vigorous wash, the currents recovered (right). $C$, A representative family of transduction currents recorded after application of INTG-His.

for hair cell mechanotransduction, we used recovery of transduction current after chemical disruption of tip links as an assay. Since newly synthesized protein is not necessary for the recovery of transduction, we reasoned that an abundance of exogenous protein fragments might interact specifically with native cadherins to prevent the reformation of tip links by outcompeting the endogenous binding partner. Specifically, we predicted that exogenous extracellular $\mathrm{CDH} 23$ fragments would outcompete native full-length $\mathrm{CDH} 23$ and thus prevent formation of $\mathrm{CDH} 23$ / PCDH15 filaments (Fig. 3A, diagram). Likewise, extracellular addition of PCDH15 fragments was predicted to outcompete endogenous PCDH15 and block formation of full-length filaments (Fig. 3B, diagram).

To test these predictions, we first treated mouse cochlear hair cells with $5 \mathrm{~mm}$ EGTA for $15 \mathrm{~min}$. The cells were then incubated for $12 \mathrm{~h}$ in a solution that contained $1.3 \mathrm{~mm}$ calcium and purified $\mathrm{CDH} 23$ fragments (CDH23-His), which included the full-length CDH23 ectodomain (supplemental Fig. 1, available at www. jneurosci.org as supplemental material). We recorded from 19 hair cells and found that the mean maximal transduction current was $-156 \pm 36 \mathrm{pA}$, a significant $(p<0.0001)$ reduction relative to the currents in hair cells that were not exposed to CDH23-His (Fig. 3A) (see also Fig. 5A). We found a similar significant $(p<$ $0.0001)$ reduction in the maximal transduction current amplitude $(-178 \pm 38 \mathrm{pA}, n=17)$ when the cells were exposed to purified PCDH15 ectodomain fragments (PCDH15-His) (supplemental Fig. 1, available at www.jneurosci.org as supplemental material) for $12 \mathrm{~h}$ (Fig. 3B) (see also Fig. 5A). As a control for the specificity of the interaction between the exogenous fragments and endogenous proteins, we used a purified integrin fragment (INTG-His) that was generated and purified in the same manner. We found no significant $(p=0.6)$ reduction of the transduction current recovery relative to untreated controls: the mean maximal transduction current after exposure to INTG-His was $-375 \pm 29 \mathrm{pA}(n=28)$ (Fig. $3 C$ ) (see also Fig. 5A). These data suggest that the recovery of transduction can be inhibited by extracellular application of CDH23 or PCDH15 fragments but not integrin, consistent with the notion that a functional interaction between endogenous $\mathrm{CDH} 23$ and $\mathrm{PCDH} 15$ is required for the recovery of hair cell transduction after chemical disruption of tip links.

To control for the possibility that the His tag may have affected transduction recovery, we also applied $\mathrm{CDH} 23$ or 
PCDH15 fragments that lacked a His tag. In this case, the fragments were tagged with the Fc domain of human IgG (supplemental Fig. 1, available at www.jneurosci.org as supplemental material). Both Fc-tagged fragments induced significant inhibition in transduction current recovery (CDH23F11-Fc: $-229 \pm$ $53 \mathrm{pA}, n=10, p=0.016$; PCDH15-Fc: $-221 \pm 25 \mathrm{pA}, n=25$, $p=0.00015)$ similar to the His-tagged fragments, which minimized the concern that the inhibition was the result of the tag itself.

The transduction currents that recovered during incubation with $\mathrm{CDH} 23$ or PCDH15 fragments had normal activation curves and normal adaptation. Since a reduction in the whole-cell current amplitude was the only effect observed, we interpret these data to suggest that the total number of functional transduction units per cell was reduced. The alternate explanation-that each hair cell had the same number of functional transduction units before and after application of $\mathrm{CDH} 23$ or PCDH15 fragments, but that there was a reduction in current per transduction unitseems less likely, since the biophysical properties were otherwise unaltered.

We also found that the decrease in transduction current recovery depended on the concentration of the protein fragments applied to the cultures. At higher concentrations of CDH23-His, the inhibition of transduction current recovery was more pronounced. A dose-response curve fitted with an exponential indicated a half-maximal inhibition dose of $13.6 \mathrm{ng} / \mu \mathrm{l}$, which corresponds to a concentration of $\sim 40 \mathrm{~nm}$ (Fig. $5 B$ ).

Next, we wondered whether the interaction between $\mathrm{CDH} 23$ and PCDH15 was dynamic or stable. To investigate this question, we performed the same experiments except that hair bundles were not exposed to EGTA. In other words, tip links remained intact before the $12 \mathrm{~h}$ incubation with the protein fragments. In this case, we observed no reduction on the mean maximal transduction current amplitudes in any of the three conditions: CDH23-His: $-425 \pm 28 \mathrm{pA},(n=21)$; PCDH15-His: $-486 \pm 24$ pA, $(n=13)$; INTG-His: $-477 \pm 24 \mathrm{pA},(n=5)$. These data suggest that, once formed, the interaction between endogenous CDH23 and PCDH15 is fairly stable and is not vulnerable to competitive inhibition by external application of exogenous protein fragments. Furthermore, the lack of effect without prior EGTA treatment shows that neither CDH23-His nor PCHD15His had a nonspecific, blocking effect on transduction channels directly.

\section{Washout of exogenous protein fragments}

Since the inhibition of transduction recovery was robust and repeatable, we wondered whether the block could be washed out. That is, could a second treatment, with the low-calcium EGTA solution followed by a vigorous wash, break the interaction between endogenous PCDH15 and exogenous CDH23-His or between endogenous CDH23 and exogenous PCDH15-His? If so, the endogenous proteins might be available to reassemble and reform full-length functional interactions. Indeed, $24 \mathrm{~h}$ after a second treatment with the EGTA solution and vigorous wash we found that the transduction currents recovered (Fig. $3 A, B$ ) (see also Fig. $5 A$ ). The mean maximal transduction current amplitudes after washout of $\mathrm{CDH} 23$-His $(-372 \pm 24 \mathrm{pA}, n=16)$ and PCDH15-His $(-371 \pm 33 \mathrm{pA}, n=10)$ were similar and were not significantly $(p>0.05)$ different from washout of INTG controls $(-423 \pm 12 \mathrm{pA}, n=3)$.

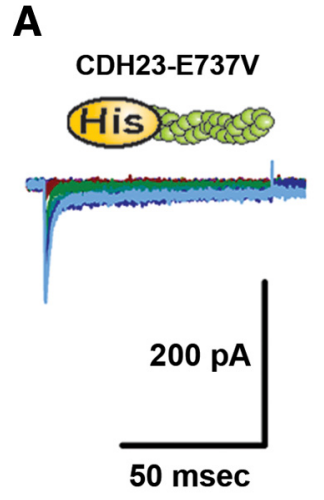

B PCDH15-R139G

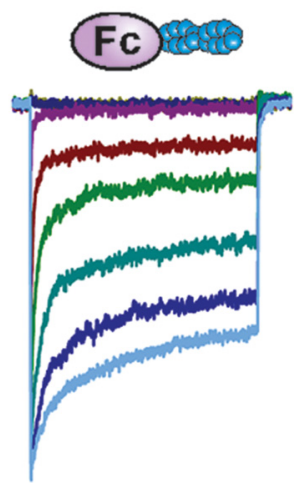

Figure 4. Effects of mutations in $\mathrm{CDH} 23$ and $\mathrm{PCDH} 15$ fragments. $\boldsymbol{A}$, A form of $\mathrm{CDH} 23$ - His that carried the salsa mutation (E737V) was applied to hair bundles after the EGTA treatment. A representative family of transduction currents showed reduction in current amplitude. Presumably, the mutation in the seventh EC domain did not affect binding to endogenous PCDH15. Bundles were deflected in $0.2 \mu \mathrm{m}$ steps that ranged between -0.2 and $1.2 \mu \mathrm{m}$. The scale bar and stimulus protocol apply to both families of transduction currents. $\boldsymbol{B}$, In this case a PCDH15-Fc that carried a mutation (R139G) in the first cadherin domain was added after EGTA treatment. The equivalent mutation causes DFNB23 in humans. A representative family of transduction currents with normal amplitudes is shown on the right. It is hypothesized that the mutation prevented binding to the $\mathrm{N}$ terminus of $\mathrm{CDH} 23$, which allowed the endogenous molecules to reform functional tip links.

\section{Mutations in $\mathrm{CDH} 23$ and PCDH15 that cause deafness}

Next, we examined the effects of two missense mutations. E737V occurs in the seventh EC domain of CDH23 and causes deafness in salsa mice (Schwander et al., 2009), a model of the nonsyndromic, recessive deafness in humans known as DFNB12. The second mutation we examined, R139G, occurs in the putative interaction domain (EC1) of PCDH15 and causes the nonsyndromic recessive deafness DFNB23 in humans (Ahmed et al., 2003). salsa mice have normal hair bundle morphology and normal transduction current amplitudes at early postnatal stages (Schwander et al., 2009). Interestingly, the CDH23 mutation in the seventh cadherin domain affects calcium binding and is thought to render the molecule susceptible to mechanical damage, accumulation of which may be the cause of the deafness that occurs at later stages (Schwander et al., 2009). The presence of normal transduction current amplitudes at early postnatal stages suggests that $\mathrm{CDH} 23$ is functional at these stages and that the E737V mutation does not affect its ability to bind PCDH15. To examine the ability of mutant $\mathrm{CDH} 23$ to interact with PCDH15, we used our standard assay and applied $\mathrm{CDH} 23$ fragments that carried the salsa mutation (CDH23-E737V). The fragments were applied for $12 \mathrm{~h}$ after treatment with the low-calcium, EGTA solution. We found that the $\mathrm{CDH} 23-\mathrm{E} 737 \mathrm{~V}$ fragments blocked the recovery of transduction in a manner similar to the wild-type $\mathrm{CDH} 23$-His fragments. The mean maximal transduction currents were significantly reduced $(-178 \pm 49 \mathrm{pA}, n=11, p<$ 0.005 ) (Figs. $4 A, 5 A$ ) relative to controls. Since application of the exogenous $\mathrm{CDH} 23-\mathrm{E} 737 \mathrm{~V}$ fragments inhibited the recovery of transduction, we conclude that the E737V mutation does not disrupt the functional interaction with endogenous cadherin molecules in hair cells, which is consistent with available biochemical data (Schwander et al., 2009). As such, our data help explain the presence of normal transduction current amplitudes in salsa mice as reported by Schwander et al. (2009). Furthermore, these data are consistent with the suggestion that the mutation, in the seventh cadherin domain, affects the mechanical properties of molecule but not its ability to bind PCDH15. 


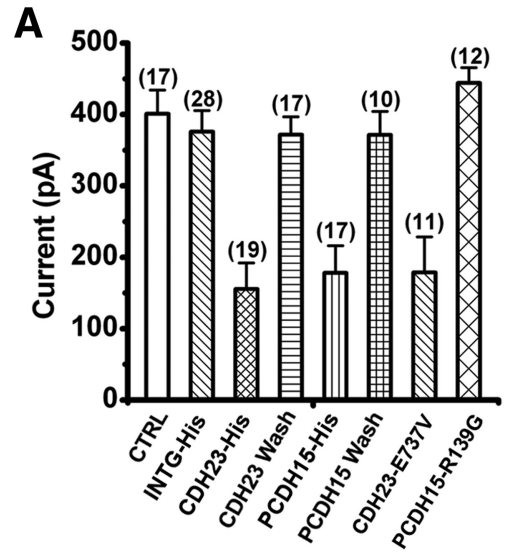

B

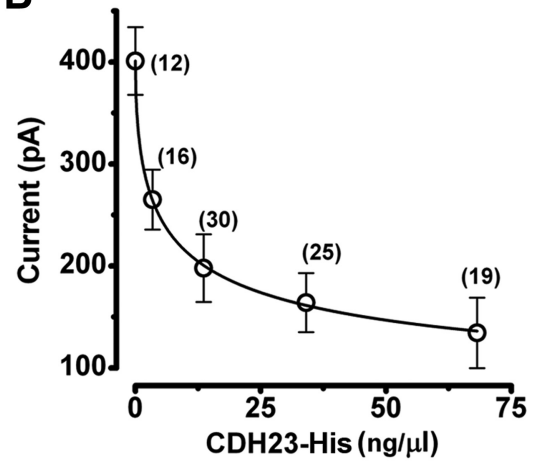

Figure 5. Summary bar graph and dose-response relation for $\mathrm{CDH} 23$ fragments. $A$, Bar graph that summarizes mean maximal transduction current amplitudes in the various conditions presented in Figures 1-4. CTRL, Control (no fragments added); INTG-His, integrin fragments; $\mathrm{CDH} 23$-His, cadherin 23 fragments; $\mathrm{CDH} 23$ Wash, washout of CDH23-His; PCDH15-His, protocadherin 15 fragments; $\mathrm{PCDH} 15$ Wash, washout of $\mathrm{PCDH} 15-\mathrm{His}$; $\mathrm{CH} 23-\mathrm{E} 737 \mathrm{~V}$, $\mathrm{CDH} 23$ fragments that carry the salsa mutation; and PCDH15R139G, PCDH15 fragments that carry the DFNB23 mutation in EC1. The number of cells examined in each condition is shown above each bar. Error bars indicate SE. $\boldsymbol{B}$, Mean maximal amplitude of currents recorded $12 \mathrm{~h}$ after EGTA treatment plotted as a function of the concentration of $\mathrm{CDH} 23$-His solution added to the media. Higher concentrations decreased the current amplitude in a dose-dependent manner. The zero concentration corresponds to control experiments. Data from CDH23-His and CDH23-E737V were pooled since their effect was indistinguishable. The number of cells examined in each condition is shown next to each data point. Error bars indicate SE. The data were fitted with a logistic curve: $y=A_{2}+\left(A_{1}-A_{2}\right) /\left(1+\left(x / x_{0}\right)^{\mathrm{p}}\right) ; A_{1}=-401 \mathrm{pA} ; \mathrm{A2}=$ $-58.4 \mathrm{pA} ; x_{0}=13.6 \mathrm{ng} / \mu \mathrm{l} ; p=0.53$.
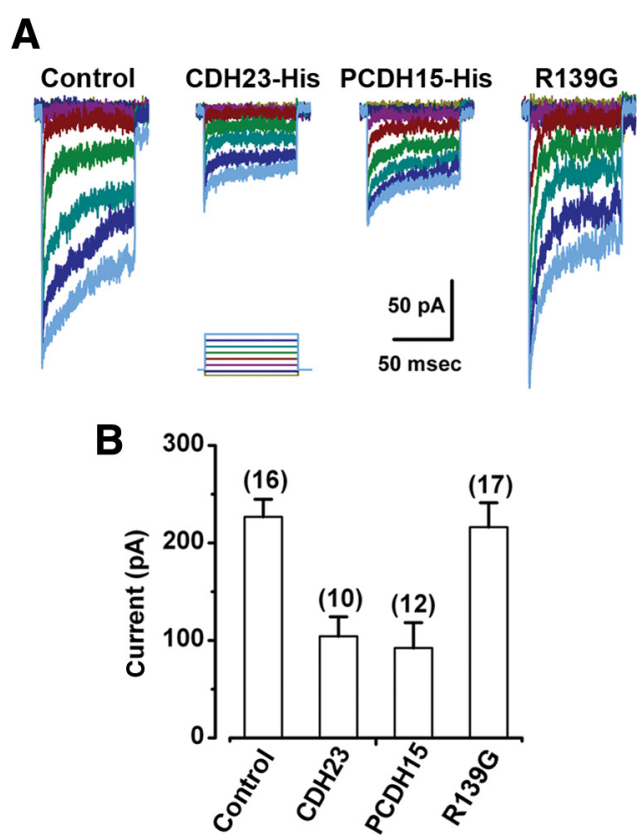

Figure 6. Transduction current development is impaired by $\mathrm{CDH} 23$ and $\mathrm{PCDH} 15$ fragments. A, Representative families of transduction currents recorded from apical outer hair cells. Cochleas were harvested before the onset of mechanotransduction (PO) and cultured with media supplemented with control solution, $\mathrm{CDH} 23$ fragments (CDH23-His), $\mathrm{PCDH} 15$ fragments (PCDH15-His), or PCDH15 that carried a DFNB23 mutation (PCDH15-R139G). Transduction currents were recorded after $3 \mathrm{~d}$ in culture. The stimulus protocol is shown at the bottom of each dataset: $0.2 \mu \mathrm{m}$ steps from $-0.2 \mu \mathrm{m}$ to $1.2 \mu \mathrm{m}$. $\boldsymbol{B}$, Bar graph illustrating the mean maximal transduction current amplitude in the different experimental conditions shown in $\boldsymbol{A}$. The number of cells for each condition is shown above the bars. Error bars show SE.

In contrast, mutations in PCDH15 that cause DFNB23 can occur in either the first or second cadherin domain but only those that occur in the first cadherin domain abolish the interaction with CDH23 in vitro (Kazmierczak et al., 2007). As a control for nonspecific effects and to gain insight into the etiology of DFNB23, we applied exogenous PCDH15 fragments that carried the R139G mutation in the first cadherin domain (PCDH15-R139G). Twelve hours after exposure to the low-calcium EGTA solution and application of the PCDH15R139G fragments, we observed no reduction in the mean maximal transduction currents. The currents recovered to control levels $(-444 \pm 21 \mathrm{pA}, n=12)$ (Fig. $4 B)$. This finding suggests that the inhibition of transduction current recovery observed after incubation with the wild-type PCDH15-Fc fragments was not due to a nonspecific interaction since, except for the mutation, the experiments were identical. Furthermore, the lack of inhibition suggests that R139G mutation renders PCDH15 unable to bind endogenous $\mathrm{CDH} 23$, consistent with the conclusions of Kazmierczak et al. (2007).

\section{Development of transduction}

Since recovery of transduction was inhibited by external application of exogenous CDH23 and PCDH15 fragments, we wondered whether development of transduction might also be vulnerable to inhibition. To test whether a functional interaction between $\mathrm{CDH} 23$ and PCDH15 is required for the development of transduction, we examined four conditions. In this case, the apical region of the mouse cochlea was excised at $\mathrm{P} 0$, before the developmental onset of mechanotransduction in mouse outer hair cells (Lelli et al., 2009). The organs of Corti were placed in culture for $3 \mathrm{~d}$ and were exposed to CDH23-His, PCDH15-His, a control solution that contained neither, or PCDH15-R139G fragments. Transduction currents were recorded at the equivalent of P3 after application of the various protein fragments. We found that hair cells exposed to either CDH23-His or PCDH15-His had maximal transduction currents that were significantly reduced $(p<0.0005)$ relative to untreated controls and relative to cells exposed to either the control solution or the PCDH15-R139G fragments (Fig. 6). We conclude that a functional interaction between $\mathrm{CDH} 23$ and PCDH15 is required for the normal development of transduction currents and that the interaction is established extracellularly.

\section{Localization of CDH23 and PCDH15 fragments}

Data presented in the previous sections suggest that a functional interaction between $\mathrm{CDH} 23$ and PCDH15 is required for both development and regeneration of hair cell transduction. Other recent work has suggested that these molecules are localized at the tips of stereocilia and that they are thought to interact to form tip links (Kazmierczak et al., 2007), which are essential for transduction (Assad et al., 1991). However, CDH23 and PCDH15 are also localized elsewhere in the hair bundle and may play a key role in the formation of proper hair bundle morphology during development (Bolz et al., 2001; Di Palma et al., 2001; Lagziel et al., 2005; Michel et al., 2005). Therefore, we wondered whether the inhibition we observed was the result of interactions between $\mathrm{CDH} 23$ or PCDH15 fragments and endogenous PCDH15 and $\mathrm{CDH} 23$ located at the tips of stereocilia or elsewhere in the bundle. To localize the exogenous protein fragments, we fixed cul- 
tured organs of Corti after the tip links had been cut by EGTA and tissue had been exposed to CDH23F11-Fc, PCDH15-Fc, or PCDH15-R139G-Fc fragments for $12 \mathrm{~h}$. Since we observed similar transduction current inhibition between His-tagged fragments and Fc-tagged fragments, we opted to use fragments fused to the Fc domain of human IgG (Kazmierczak et al., 2007) and an antibody against the human Fc domain conjugated to FITC to localize the exogenous fragments. The tissue was counterstained with phalloidin-Alexa 546 to illuminate the hair bundles. Figure $7 \mathrm{~A}$ shows immunoreactivity for $\mathrm{CDH} 23 \mathrm{~F} 11-\mathrm{Fc}$ at the tips of the stereocilia and in the kinocilium, revealing the localization pattern of its endogenous binding partner, presumably PCDH15. We observed punctate staining at the tips of the outer hair cell stereocilia and in the kinocilium but not elsewhere in the bundle. The pattern was consistent with the data from Ahmed et al. (2006), who showed immunolocalization of PCDH15 at the tips of stereocilia and, after treatment with BAPTA, in the kinocilium.

To localize the binding partner of PCDH15-Fc, we performed essentially the same experiment using the human Fc domain antibody conjugated to FITC. The distribution of PCDH15-Fc (Fig. 7B), which presumably reflected the localization of endogenous $\mathrm{CDH} 23$, was also at the stereociliary tips. A noticeable difference was the lack of prominent immunofluorescence in the kinocilium. Last, we were unable to detect the binding of mutant PCDH15-R139G fragments (Fig. 7C), consistent with its inability to inhibit development and recovery of transduction currents. No immunofluorescence was detected in bundles incubated the human Fc domain conjugated to FITC by itself or with a control solution that did not contain protein fragments (data not shown).

\section{Presence of tip links during transduction recovery}

To determine whether inhibition of transduction corresponded to inhibition of tip-link recovery, we used scanning electron microscopy to collect images of hair bundles under control conditions, immediately after exposure to the low-calcium EGTA solution, $12 \mathrm{~h}$ after exposure to the EGTA solution, and $12 \mathrm{~h}$ after EGTA in the presence of CDH23-His or PCDH15-Fc (Fig. 8A). Importantly, incubation with $\mathrm{CDH} 23-\mathrm{His}$ or PCDH15-Fc did not disrupt normal hair bundle morphology (Fig. $8 \mathrm{~A}$ ). At high magnification, a myriad of linkages between adjacent stereocilia in many different orientations were apparent, consistent with previous reports of developing cochlear hair bundles (Goodyear et al., 2005). Thus, we were unable to conclusively distinguish true tip links from the numerous other linkages present at this developmental stage. However, at higher magnification it was clear that control bundles contained numerous links oriented parallel to the morphological axis of sensitivity of the bundles (Fig. $8 \mathrm{~B}$, arrows). Immediately after EGTA treatment, the number of linkages with such orientation was greatly reduced and sites between adjacent stereocilia where tip links might be found (arrows) were mostly vacant. Twelve hours after exposure to
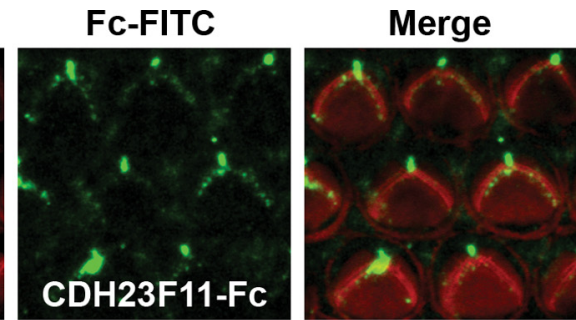

High Mag
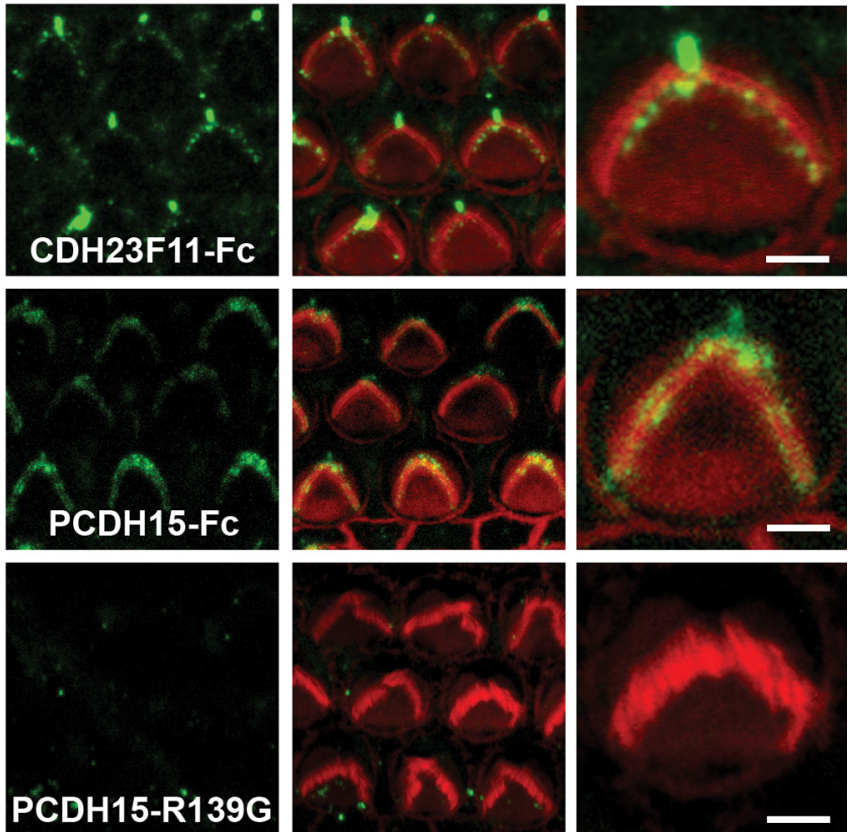

PCDH15-R139C

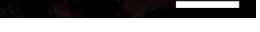

Figure 7. Binding of $\mathrm{CDH} 23$ and $\mathrm{PCDH} 15$ fragments to hair bundles. Confocal images of cultures fixed $12 \mathrm{~h}$ after EGTA treatment 作 fluorescence in samples treated with fragments. The third column shows the merge of the Alexa Fluor 546 channel and the FITC 1 cadherin domains of $\mathrm{CDH} 23$ fused to an $\mathrm{Fc}$ domain. $\boldsymbol{B}$, The entire ectodomain of $\mathrm{PCDH} 15$ fused to the $\mathrm{Fc}$ domain. $\boldsymbol{C}, \mathrm{PCDH} 15-$

the EGTA solution, linkages oriented along the morphological axis of the bundle were again apparent (arrows). Consistent with our physiological data, we found that bundles exposed to PCDH15-Fc had fewer linkages aligned along the morphological axis of the bundle. A few pairs of stereocilia did contain links which was consistent with the partial transduction currents that remained after $\mathrm{CDH} 23-\mathrm{His}$ and $\mathrm{PCDH} 15-\mathrm{Fc}$ treatment.

To quantify apparent tip links, we examined pairs of stereocilia in the tallest three rows. We counted the proportion of potential tip-link sites that were occupied by links oriented parallel to the sensitive axis. Hair bundles were scored by two independent observers, and the counts for each bundle were averaged. We examined 37 bundles in five conditions and present the data as a bar graph (Fig. 8C). Consistent with the data from chick hair bundles (Zhao et al., 1996), we found few occupied tip-link sites in bundles just after exposure to EGTA but significant recovery $12 \mathrm{~h}$ later. When cells were exposed to CDH23-His or PCDH15$\mathrm{Fc}$, the proportion of occupied sites was significantly reduced $(p<0.005)$. Based on the general preservation of the hair bundle morphology and the lack of occupied tip-link sites, we conclude that the inhibition in the development and recovery of transduction currents was the result of an acute and specific inhibition of tip-link formation rather than the result of chronic structural disruption of hair bundle morphology.

\section{Discussion}

Transduction recovery parallels development

Here, we have identified a number of similarities between the time course and properties of transduction recovery with those of transduction development (Lelli et al., 2009), which leads us to propose that the two functions may share similar mechanisms. 


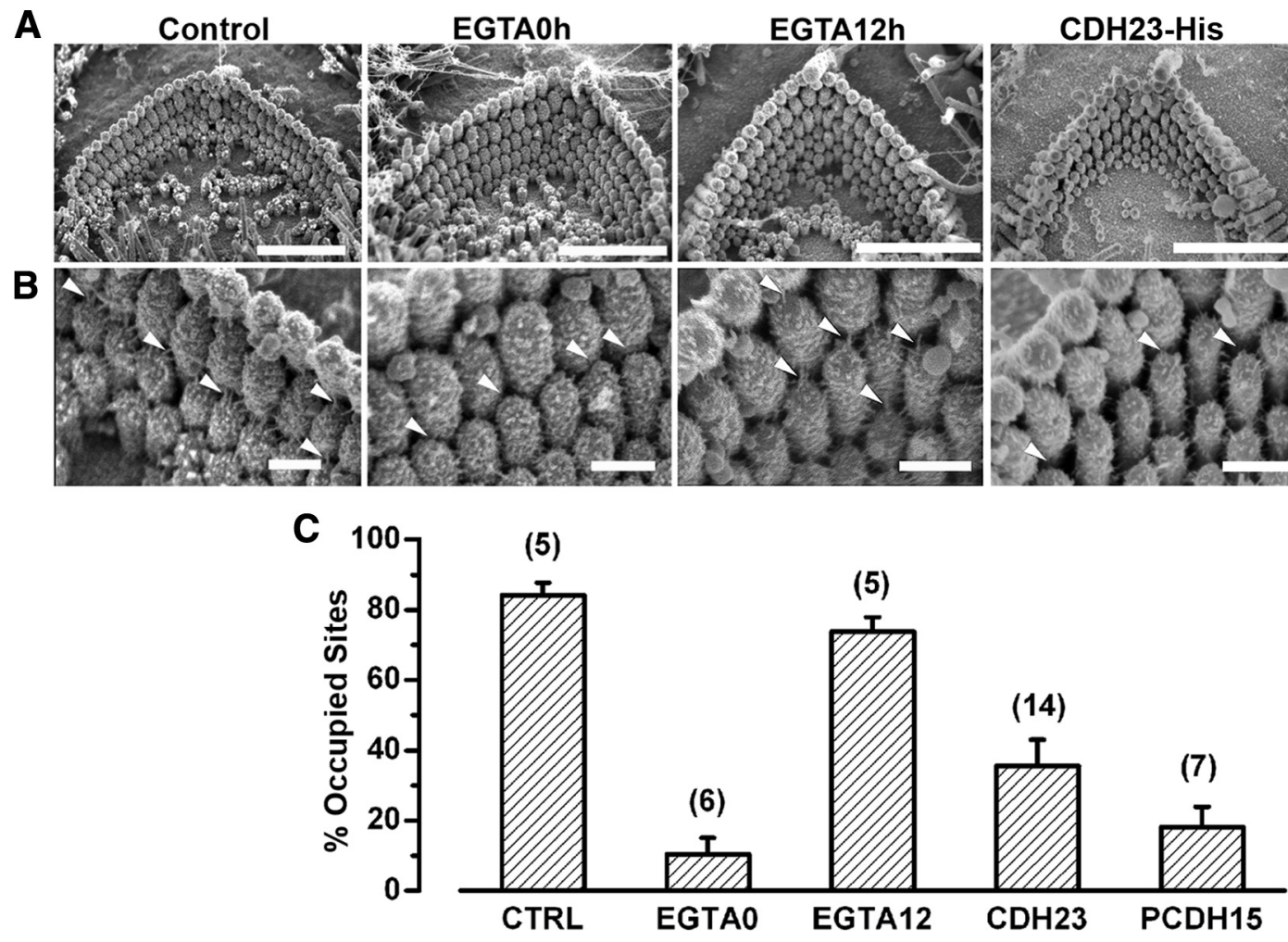

Figure 8. Fragments prevent recovery of tip links after EGTA treatment. $\boldsymbol{A}$, Scanning electron micrographs of outer hair cell bundles. Scale bars, $2 \boldsymbol{\mu m}$. $\boldsymbol{B}$, Higher magnification views of the samples shown in $\boldsymbol{A}$. Scale bars, $300 \mathrm{~nm}$. Linkages (white arrows) connecting the tips of hair cell stereocilia were apparent in untreated samples (control), but were absent in samples fixed immediately after EGTA treatment (EGTAOh). Arrows indicate unoccupied tip-link sites. Several cultures were allowed $12 \mathrm{~h}$ of recovery after EGTA treatment (EGTA12h) and linkages reappeared (arrows). When $\mathrm{CDH} 23$-His and PCDH15-Fc were added during the recovery period, only a few links reformed, whereas links oriented along the axis of symmetry of the bundle were absent between most pairs of stereocilia (arrows). C, The percentage of occupied tip-link sites was quantified for each experimental condition: control (CTRL), immediately after EGTA treatment (EGTA0), $12 \mathrm{~h}$ after EGTA treatment (EGTA12), $12 \mathrm{~h}$ after EGTA, incubated with CDH23-His for $12 \mathrm{~h}$ after EGTA treatment, and incubated with PCDH15-Fc for $12 \mathrm{~h}$ after EGTA treatment. The number of bundles examined in each condition is indicated. Error bars indicate SE.

Furthermore, since all the qualitative properties of hair cell transduction were present as early as $3 \mathrm{~h}$ after the disruption of tip links, we suggest that the molecular correlates of these functions are intimately linked during the recovery process. In previous work, all the properties of mature transduction were found to be present at the developmental onset of mechanotransduction in both mouse vestibular (Géléoc and Holt, 2003) and auditory hair cells (Lelli et al., 2009). By adding the regeneration of transduction to this list, the notion that hair cell transduction requires a closely associated complex is strengthened. These results differ from the model for transduction development presented by Waguespack et al. (2007), who suggested a process in which the properties of hair cell transduction are acquired sequentially in discrete steps.

The quantitative properties of transduction and adaptation mature after the first appearance of currents. The following scenario could account for the increased speed of adaptation as well as the greater transduction sensitivity that occurs during development and regeneration. Transduction units minimally consist of a channel, probably at the lower end (Beurg et al., 2009), a tip link, and an adaptation motor-perhaps myosin $1 \mathrm{c}$-at the upper end (Holt et al., 2002; Stauffer et al., 2005). As individual transduction units are assembled and inserted during development or regeneration, they would be immediately functional but their adaptation motors at the upper end of the tip link would lack a calcium source until additional transduction channels are inserted above, at the tip of the same stereocilium. As more transduction units are inserted, more adaptation motors would have a calcium source within sufficient proximity to regulate adaptation. Since both adaptation rate and transduction sensitivity are greater with higher intracellular calcium, acquisition of more transduction units would tend to speed up adaptation rates and enhance sensitivity. This general scheme could also explain the slower adaptation rates and broader stimulus-response relations previously documented for smaller amplitude transduction currents during development (Lelli et al., 2009).

\section{CDH23 and PCDH15 are tip-link components}

We present three lines of evidence that further support the hypothesis that tip links are composed of $\mathrm{CDH} 23$ and PCDH15: (1) after breakage of tip links with EGTA, exogenous fragments of $\mathrm{CDH} 23$ and PCDH15 bind near the tips of hair cell stereocilia; (2) when hair cells were exposed to either $\mathrm{CDH} 23$ or PCDH15 fragments after EGTA treatment, the number of properly oriented linkages at the tips of hair cell stereocilia — presumably bona fide tip links-was greatly reduced; and (3) transduction current amplitudes were significantly reduced after application of $\mathrm{CDH} 23$ or PCDH15 fragments, either during development or regeneration. Together with previous immunolocalization of $\mathrm{CDH} 23$ and PCDH15 at the upper and lower ends of tip links, respectively, and biochemical data that demonstrate the two molecules bind at their N termini (Kazmierczak et al., 2007), our data strongly support the idea that tip links are formed by a functional interaction between cadherin- 23 and protocadherin- 15 .

Nonetheless, we wondered whether it was possible that the inhibition of transduction recovery was mediated by loss of link- 
ages elsewhere in the bundle. Horizonal top connectors, transient lateral links, and ankle links are all extracellular filaments that connect adjacent stereocilia (Goodyear et al., 2005). Since application of CDH23 and PCDH15 fragments inhibited transduction after EGTA treatment, the effect might result from disruption of ankle links, the only other hair bundle links ruptured by low calcium (Goodyear et al., 2005). However, ankle links are absent in mature hair bundles and vestibular hair bundles, suggesting they are not required for mechanotransduction (Goodyear et al., 2005). Furthermore, previous work has suggested that ankle links are composed of the very large G-protein receptor 1 (McGee et al., 2006; Michalski et al., 2007) and that they may be important for cochlear hair bundle development. Although we did not examine ankle links in scanning electron microscope images of hair bundles, we did not detect immunolocalization of CDH23F11-Fc or PCDH15-Fc in the vicinity of ankle links. We think it unlikely that the inhibition of transduction recovery by $\mathrm{CDH} 23$ or PCDH15 fragments after EGTA treatment was the result of ankle link disruption.

Might $\mathrm{CDH} 23$ or PCDH15 contribute to transient lateral links? Possibly, yet since these linkages are not vulnerable to calcium chelation and since application of $\mathrm{CDH} 23$ and PCDH15 fragments had no effect on bundles that were not treated with EGTA, we consider disruption of transient lateral links an unlikely explanation. Last, $\mathrm{CDH} 23$ and PCDH15 may contribute to formation of kinociliary links. Although we did note binding of CDH23F11-Fc to kinocilia, we suspect the CDH23 and PCDH15 fragment effect on transduction recovery was not the result of disruption of kinociliary links. Kinocilia are lost during development of cochlear hair bundles and are not required for mechanotransduction (Hudspeth and Jacobs, 1979); thus, it seems unlikely that disruption of kinociliary links would lead to loss of transduction.

We further wondered whether the $\mathrm{CDH} 23$ and PCDH15 fragments might affect transduction channels directly. Since both fragments had similar effects on transduction current amplitudes and neither fragment had an effect on transduction currents without prior EGTA treatment, the likelihood that they block or directly inhibit transduction channels is low. Moreover, the notion that such a direct effect on transduction channels would be abolished by a single point mutation in PCDH15 seems even less likely.

The most parsimonious explanation is that the exogenous CDH23 and PCDH15 fragments blocked formation of tip links by competitive inhibition with the endogenous full-length molecules. Kazmierczak et al. (2007) showed that CDH23 and PCDH15 fragments exist as parallel homodimers in normal calcium concentrations and that the endogenous molecules are transported to the cell surface as stable homodimers. Therefore, we suggest that the mechanism of competitive inhibition is through N-terminal trans interactions between $\mathrm{CDH} 23$ fragments and endogenous PCDH15 or between PCDH15 fragments and endogenous $\mathrm{CDH} 23$.

\section{Mechanisms of tip-link formation}

Our data further suggest that the interaction between $\mathrm{CDH} 23$ and PCDH15 during tip-link formation is established extracellularly. Since both development and regeneration of transduction are vulnerable to inhibition by extracellular application of CDH23 and PCDH15 fragments, we can rule out intracellular formation of full-length tip-link filaments. Once established, the interaction appears stable, as application of fragments in the absence of EGTA treatment did not disrupt transduction. Exactly how and when the interaction is established in vivo has yet to be determined. One model (Denk et al., 1995) might include transduction molecules at either end of the tip link that climb up the sides of stereocilia, perhaps carried by motor molecules that are also known binding partners. At the upper end, $\mathrm{CDH} 23$ may interact with myosin 1c (Siemens et al., 2004, Phillips et al., 2006), whereas at the lower end PCDH15 may be transported by myosin15a (Belyantseva et al., 2003; 2005), myosin-3a (Schneider et al., 2006), or myosin 7a (Senften et al., 2006). At the start of their respective journeys, the separation at the base of adjacent stereocilia is too great for $\mathrm{CDH} 23 / \mathrm{PCDH} 15$ filaments to span the distance. However, as the separate molecules ascend stereocilia, hair bundle geometry is such that adjacent stereocilia are in closer proximity, in which case random thermal motion may bring the $\mathrm{N}$ termini within range to establish an interaction between the two molecules. Motors may continue to climb, tip-link and transduction apparatus in tow, until tip links become sufficiently tense to yield a resting open probability on transduction channels, at which point their motion would be arrested.

It is not clear whether the original endogenous $\mathrm{CDH} 23$ and PCDH15 molecules are used to regenerate tip links. However, we suggest that after tip-link breakage reduced tension would allow myosin motors at the upper end to continue to climb, carrying $\mathrm{CDH} 23$ up the side of the taller stereocilium toward the tip, out of range to reform a new tip link. If so, a pool of readily available transduction molecules may be available, waiting in the wings, to climb into position and establish a new tip link and fully functional transduction unit. Since both we and Zhao et al. (1996) found that cycloheximide did not inhibit regeneration of transduction, it suggests that new protein synthesis is not required, thereby implying the existence of a readily available pool of transduction molecules. Zhao et al. (1996) speculated that loss of transduction units would eliminate a calcium source at the tips of the bundles and that low intracellular calcium might in turn be the signal that drives transduction recovery.

In addition to the nature of the signaling mechanism and the reserve pool of transduction molecules, other important questions remain. How is proper molecular polarity established with PCDH15 at the lower end and $\mathrm{CDH} 23$ at the upper end, and what are the mechanisms that promote tip-link alignment along the morphological axis? Answers to these and other questions may provide a basis for therapeutic manipulation of transduction regeneration to enhance recovery of inner ear function after over exposure to loud sounds.

\section{References}

Ahmed ZM, Riazuddin S, Bernstein SL, Ahmed Z, Khan S, Griffith AJ, Morell RJ, Friedman TB, Riazuddin S, Wilcox ER (2001) Mutations of the protocadherin gene PCDH15 cause Usher syndrome type 1F. Am J Hum Genet 69:25-34.

Ahmed ZM, Riazuddin S, Ahmad J, Bernstein SL, Guo Y, Sabar MF, Sieving P, Riazuddin S, Griffith AJ, Friedman TB, Belyantseva IA, Wilcox ER (2003) PCDH15 is expressed in the neurosensory epithelium of the eye and ear and mutant alleles are responsible for both USH1F and DFNB23. Hum Mol Genet 12:3215-3223.

Ahmed ZM, Goodyear R, Riazuddin S, Lagziel A, Legan PK, Behra M, Burgess SM, Lilley KS, Wilcox ER, Riazuddin S, Griffith AJ, Frolenkov GI, Belyantseva IA, Richardson GP, Friedman TB (2006) The tip link antigen, a protein associated with the transduction complex of sensory hair cells, is protocadherin-15. J Neurosci 26:7022-7034.

Alagramam KN, Yuan H, Kuehn MH, Murcia CL, Wayne S, Srisailpathy CR, Lowry RB, Knaus R, Van Laer L, Bernier FP, Schwartz S, Lee C, Morton CC, Mullins RF, Ramesh A, Van Camp G, Hageman GS, Woychik RP, Smith RJ, Hagemen GS (2001) Mutations in the novel protocadherin PCDH15 cause Usher syndrome type 1F. Hum Mol Genet 10:1709-1718. 
Assad JA, Shepherd GM, Corey DP (1991) Tip link integrity and mechanical transduction in vertebrate hair cells. Neuron 7:985-994.

Belyantseva IA, Boger ET, Friedman TB (2003) Myosin XVa localizes to the tips of inner ear sensory cell stereocilia and is essential for staircase formation of the hair bundle. Proc Natl Acad Sci U S A 100:13958-13963.

Belyantseva IA, Boger ET, Naz S, Frolenkov GI, Sellers JR, Ahmed ZM, Griffith AJ, Friedman TB (2005) Myosin-XVa is required for tip localization of whirlin and differential elongation of hair-cell stereocilia. Nat Cell Biol 7:148-156.

Beurg M, Fettiplace R, Nam JH, Ricci AJ (2009) Localization of inner hair cell mechanotransducer channels using high-speed calcium imaging. Nat Neurosci 12:553-558.

Bolz H, von Brederlow B, Ramírez A, Bryda EC, Kutsche K, Nothwang HG, Seeliger M, del C-Salcedó Cabrera M, Vila MC, Molina OP, Gal A, Kubisch C (2001) Mutation of CDH23, encoding a new member of the cadherin gene family, causes Usher syndrome type 1D. Nat Genet 27:108-112.

Denk W, Holt JR, Shepherd GM, Corey DP (1995) Calcium imaging of single stereocilia in hair cells: localization of transduction channels at both ends of tip links. Neuron 15:1311-1321.

Di Palma F, Pellegrino R, Noben-Trauth K (2001) Genomic structure, alternative splice forms and normal and mutant alleles of cadherin 23 (Cdh23). Gene 281:31-41.

Furness DN, Hackney CM (1985) Cross-links between stereocilia in the guinea pig cochlea. Hear Res 18:177-188.

Furness DN, Katori Y, Nirmal Kumar B, Hackney CM (2008) The dimensions and structural attachments of tip links in mammalian cochlear hair cells and the effects of exposure to different levels of extracellular calcium. Neuroscience 154:10-21.

Gale JE, Marcotti W, Kennedy HJ, Kros CJ, Richardson GP (2001) FM1-43 dye behaves as a permeant blocker of the hair-cell mechanotransducer channel. J Neurosci 21:7013-7025.

Géléoc GS, Holt JR (2003) Developmental acquisition of sensory transduction in hair cells of the mouse inner ear. Nat Neurosci 6:1019-1020.

Goodyear RJ, Marcotti W, Kros CJ, Richardson GP (2005) Development and properties of stereociliary link types in hair cells of the mouse cochlea J Comp Neurol 485:75-85.

Holt JR, Gillespie SK, Provance DW, Shah K, Shokat KM, Corey DP, Mercer JA, Gillespie PG (2002) A chemical-genetic strategy implicates myosin-1c in adaptation by hair cells. Cell 108:371-381.

Hudspeth AJ, Jacobs R (1979) Stereocilia mediate transduction in vertebrate hair cells (auditory system/cilium/vestibular system). Proc Natl Acad Sci U S A 76:1506-1509.

Husbands JM, Steinberg SA, Kurian R, Saunders JC (1999) Tip link integrity on chick tall hair cell stereocilia following intense sound exposure. Hear Res 135:135-145.

Jia S, Yang S, Guo W, He DZ (2009) Fate of mammalian cochlear hair cells and stereocilia after loss of the stereocilia. J Neurosci 29:15277-15285.

Kazmierczak P, Sakaguchi H, Tokita J, Wilson-Kubalek EM, Milligan RA, Müller U, Kachar B (2007) Cadherin 23 and protocadherin 15 interact to form tip link filaments in sensory hair cells. Nature 449:87-91.

Lagziel A, Ahmed ZM, Schultz JM, Morell RJ, Belyantseva IA, Friedman TB (2005) Spatiotemporal pattern and isoforms of cadherin 23 in wild type and waltzer mice during inner ear hair cell development. Dev Biol 280:295-306.

Lelli A, Asai Y, Forge A, Holt JR, Géléoc GS (2009) Tonotopic gradient in the developmental acquisition of sensory transduction in outer hair cells of the mouse cochlea. J Neurophysiol 101:2961-2973.

Marquis RE, Hudspeth AJ (1997) Effects of extracellular Ca2+ concentration on hair-bundle stiffness and gating-spring integrity in hair cells. Proc Natl Acad Sci U S A 94:11923-11928.

McGee J, Goodyear RJ, McMillan DR, Stauffer EA, Holt JR, Locke KG, Birch DG, Legan PK, White PC, Walsh EJ, Richardson GP (2006) The very large G-protein-coupled receptor VLGR1: a component of the ankle link complex required for the normal development of auditory hair bundles. J Neurosci 26:6543-6553.
Michalski N, Michel V, Bahloul A, Lefèvre G, Barral J, Yagi H, Chardenoux S, Weil D, Martin P, Hardelin JP, Sato M, Petit C (2007) Molecular characterization of the ankle-link complex in cochlear hair cells and its role in the hair bundle functioning. J Neurosci 27:6478-6488.

Michel V, Goodyear RJ, Weil D, Marcotti W, Perfettini I, Wolfrum U, Kros CJ, Richardson GP, Petit C (2005) Cadherin 23 is a component of the transient lateral links in the developing hair bundles of cochlear sensory cells. Dev Biol 280:281-294.

Müller U, Wang D, Denda S, Meneses JJ, Pedersen RA, Reichardt LF (1997) Integrin alpha8betal is critically important for epithelial-mesenchymal interactions during kidney morphogenesis. Cell 88:603-613.

Pawlowski KS, Kikkawa YS, Wright CG, Alagramam KN (2006) Progression of inner ear pathology in Ames waltzer mice and the role of protocadherin 15 in hair cell development. J Assoc Res Otolaryngol 7:83-94.

Phillips KR, Tong S, Goodyear R, Richardson GP, Cyr JL (2006) Stereociliary myosin- $1 \mathrm{c}$ receptors are sensitive to calcium chelation and absent from cadherin 23 mutant mice. Neuroscience 26:10777-10788.

Pickles JO, Comis SD, Osborne MP (1984) Cross-links between stereocilia in the guinea pig organ of Corti, and their possible relation to sensory transduction. Hear Res 15:103-112.

Rzadzinska AK, Steel KP (2009) Presence of interstereocilial links in waltzer mutants suggests Cdh23 is not essential for tip link formation. Neuroscience 158:365-368.

Rzadzinska AK, Derr A, Kachar B, Noben-Trauth K (2005) Sustained cadherin 23 expression in young and adult cochlea of normal and hearingimpaired mice. Hear Res 208:114-121.

Schneider ME, Dosé AC, Salles FT, Chang W, Erickson FL, Burnside B, Kachar B (2006) A new compartment at stereocilia tips defined by spatial and temporal patterns of myosin IIIa expression. J Neurosci 26:10243-10252.

Schwander M, Xiong W, Tokita J, Lelli A, Elledge HM, Kazmierczak P, Sczaniecka A, Kolatkar A, Wiltshire T, Kuhn P, Holt JR, Kachar B, Tarantino L, Müller U (2009) A mouse model for nonsyndromic deafness (DFNB12) links hearing loss to defects in tip links of mechanosensory hair cells. Proc Natl Acad Sci U S A 106:5252-5257.

Senften M, Schwander M, Kazmierczak P, Lillo C, Shin JB, Hasson T, Géléoc GS, Gillespie PG, Williams D, Holt JR, Müller U (2006) Physical and functional interaction between protocadherin 15 and myosin VIIa in mechanosensory hair cells. J Neurosci 26:2060-2071.

Shepherd GM, Corey DP (1994) The extent of adaptation in bullfrog saccular hair cells. J Neurosci 14:6217-6229.

Siemens J, Lillo C, Dumont RA, Reynolds A, Williams DS, Gillespie PG, Müller U (2004) Cadherin 23 is a component of the tip link in hair-cell stereocilia. Nature 428:950-955.

Söllner C, Rauch GJ, Siemens J, Geisler R, Schuster SC, Müller U, Nicolson T, Tübingen 2000 Screen Consortium (2004) Mutations in cadherin 23 affect tip links in zebrafish sensory hair cells. Nature 428:955-959.

Sotomayor M, Weihofen WA, Gaudet R, Corey DP (2010) Structural determinants of cadherin-23 function in hearing and deafness. Neuron 66:85-100.

Stauffer EA, Holt JR (2007) Sensory transduction and adaptation in inner and outer hair cells of the mouse auditory system. J Neurophysiol 98:3360-3369.

Stauffer EA, Scarborough JD, Hirono M, Miller ED, Shah K, Mercer JA, Holt JR, Gillespie PG (2005) Fast adaptation in vestibular hair cells requires myosin-1c activity. Neuron 47:541-553.

Vollrath MA, Eatock RA (2003) Time course and extent of mechanotransducer adaptation in mouse utricular hair cells: comparison with frog saccular hair cells. J Neurophysiol 90:2676-2689.

Waguespack J, Salles FT, Kachar B, Ricci AJ (2007) Stepwise morphological and functional maturation of mechanotransduction in rat outer hair cells J Neurosci 27:13890-13902.

Zhao Y, Yamoah EN, Gillespie PG (1996) Regeneration of broken tip links and restoration of mechanical transduction in hair cells. Proc Natl Acad Sci U S A 94:15469-15474. 